\title{
Psychological Mindedness and Abstract Reasoning in Late Childhood and Adolescence: An Exploration Using New Instruments
}

\author{
Robert Hatcher, ${ }^{1,6}$ Sherry Hatcher, ${ }^{2}$ Meryl Berlin, ${ }^{3}$ Katherine Okla, ${ }^{4}$ \\ and Jill Richards ${ }^{5}$
}

Received May 26, 1988; accepted November 14, 1989

This study introduces two new measures of psychological mindedness, applying them in a study of the growth of abstract thinking in children and adolescents in a developmental design. The capacity to achieve psychological understanding of the self and of others involves comprehension of the motives, attitudes, and characteristics of the self and others. Psychological mindedness toward the self (PS) and toward others (PO) may be seen as complex cognitive capacities that should show a pattern of related development in childhood. Three groups of $60 \mathrm{fifth}$, eighth, and twelfth graders completed two measures of formal operations and two instruments to assess the two components of psychological mindedness. We find that psychological mindedness and abstract thinking both increase significantly with age, although

\footnotetext{
${ }^{1}$ Director, Psychological Clinic, The University of Michigan. Received Ph.D. from University of Michigan and psychoanalytic training from The Michigan Psychoanalytic Institute. Main research interests are psychoanalytic theory, the therapeutic alliance, and insight and selfobservation.

${ }^{2}$ Lecturer, Department of Psychology, The University of Michigan. Received Ph.D. from University of Michigan. Main research interests are adolescent development, peer counseling, shortterm psychotherapy, and the psychology of women.

${ }^{3}$ Department of Psychology, The University of Michigan. Received M.A. from The University of Michigan. Main research interests are infant mental health and attachment theory.

${ }^{4}$ Department of Psychology, The University of Michigan. Received M.A. from The University of Michigan. Main research interests are gender identity and children of divorce.

${ }^{5}$ Received B.A. from The University of Michigan. Main research interests are gender issues and adolescent development.

6To whom correspondence should be addressed at The University of Michigan Psychological Clinic, 1027 E. Huron, Ann Arbor, MI 48104-1688.
} 
the relationship between them is complex and varies with gender and age. Because the development of abstract reasoning skills does not correlate with the development of psychological mindedness in a simple way, a more complex model is necessary, taking age and gender differences into account. Performance on the two measures of psychological mindedness is found to be largely unrelated, suggesting that these are two different psychological skills. Implications of these findings are discussed, with special reference to education, peer counseling, and psychotherapy.

\section{INTRODUCTION}

This study introduces new measures of psychological mindedness, and applies them in a study of the growth of psychological mindedness in a broader cognitive-developmental framework. Psychological mindedness may be viewed as the capacity to achieve psychological understanding of the self and of others. Psychological understanding involves comprehension of the motives, attitudes, and characteristics of the self and others. Psychological mindedness toward the self (PS) and toward others (PO) may be seen as complex cognitive capacities that should show a pattern of related development in childhood. These considerations raise the issue of how children may be expected to make use of psychotherapies designed to increase selfunderstanding. The discussion of the results takes special interest in this question.

\section{Piagetian Background}

The theory that formal operational thought and the capacity to introspect typically emerge together during adolescence (Piaget, 1969) is widely accepted (e.g., Adelson and Doehrman, 1980; Spiegel, 1951; Elkind, 1980; Damon and Hart, 1982). Work in this area grew out of Piaget's interest in demonstrating integrated patterns of cognitive development across broad domains of functioning (e.g., Inhelder and Piaget, 1958; Niemark, 1975; Piaget, 1972).

Early Piagetian research concentrated on the child's increasingly accurate understanding of physical causality. Later work extended to many areas of the child's conception of social, moral, and psychological causality, exploring such issues as children's judgments of kindness in others (Baldwin and Baldwin, 1970), role-taking abilities (Flavell et al., 1968; Miller et al., 1970; Salatas and Flavell, 1976; Selman and Byrne, 1974) and the understanding of intention and motivation in others (King, 1971; Whiteman, 1967). (See also Adelson and O'Neil, 1966; Goldschmid, 1968; Kohlberg, 1964; Rothen- 
berg, 1970; Whiteman, 1967.) These abilities were generally found to parallel Piagetian levels of cognitive development.

Case (1985) has elaborated and systematized some of Piaget's basic findings, extending the demonstration of common patterns of development across a wide range of cognitive capacities. While some work has been done by Case and his co-workers on the development of self-understanding, it has been rather limited in scope.

\section{Approaches to the Study of Self-Understanding}

Damon and Hart's (1982) review of research on self-understanding highlights two trends. The development of self-understanding has been assumed to parallel the advance in the understanding of others, and research on the self-concept has dealt with self-esteem rather than self-understanding more generally.

Several major trends are apparent in the research on the development of self-understanding. In late childhood, there is a shift from seeing the self as a collection of physical attributes and action capacities to a recognition of the difference between the outside world and the mind of the individual. At the onset of adolescence there is a global undifferentiated sense of the mind. There is a sense of the mind's power to reflect on and control itself, but a lack of recognition of the complexities and contradictions in oneself. In later adolescence we find a capacity first to recognize, and later to resolve, these complexities and contradictions, using increasingly complex conceptualizations of the self. These resolutions recognize that people do things for reasons they do not understand, and have feelings and ideas they cannot control (Bernstein, 1980; Broughton, 1980; Selman, 1971; Secord and Peevers, 1974; Damon and Hart, 1982).

The profusion of terms in the literature on the general subject of selfunderstanding reflects different theoretical perspectives and different facets of the issue that are examined. The self can be viewed as a "psychological construct whose major function is to provide one with a cognitive sense of one's identity" (Guardo and Bohan, 1971; Damon and Hart, 1982). Here selfunderstanding is a direct reflection of the self in question, rather than an attempt to apply cognitive skills toward understanding a complex entity with independent existence in its own right, the "self." The general implication of the studies mentioned above, however, is that the growing child gains a richer and more differentiated understanding of him- or herself over time, drawing on cognitive capacities that are developing more broadly across the whole domain of his or her interests and capacities. 
Psychodynamic psychologists have a special interest in the development of self-understanding, and have given detailed attention to the internal impediments to self-awareness (R. Hatcher, 1972, 1973). Selman (1971) and others have examined the child's growing capacity to recognize and account for discrepant behaviors, attitudes, and motives in the self, but there is evidence that much younger children struggle with these issues (Kennedy, 1979; A. Freud, 1979). Self-understanding is dependent on the cognitive ability to integrate divergent aspects of the self, but it is also limited by internal resistance to recognizing unknown and less-agreeable aspects of the self. This approach raises the question of how able children are to develop and apply self-understanding in a psychotherapeutic setting.

Work with gender differences in psychological development has pointed to the effect of gender on moral development (Gilligan, 1979, 1982), and on empathic or role-taking skills (Chodorow, 1974, 1978). Females' skills are linked to their interpersonal relationships, whereas males are less interpersonal and more achievement oriented. Are there gender differences in the psychological understanding of the self and others?

Our review suggests that there is need for examination of the development of the capacity for psychological understanding of both the self and others, placing these capacities in the broader context of the development of other cognitive skills, and taking possible gender differences into account.

We view self-understanding as a cognitive capacity embedded in and affected by the rich fabric of conflicting attitudes and motives that make up the self, and make an effort to assess this influence. Our working hypothesis, however, is that the cognitive capacity of psychological mindedness will grow at the same pace in both domains. Because most cognitive capacities do not show sex differences, we do not predict them, but are prepared to analyze them should they be present. These views are represented in the following hypotheses:

1. The capacity for PS and of PO will increase with age.

2. There will be no gender differences in the capacity for abstract reasoning (verbal reasoning and spatial-mechanical reasoning), or in the capacities for PS and PO.

3. Greater capacity for abstract reasoning will be associated with greater capacity for self-understanding and for understanding others at every age level.

\section{METHOD}

\section{Subjects}

The present study is concerned with children in grades five, eight, and twelve, grade levels chosen for two reasons: (1) they are likely to demon- 
strate the various stages of cognitive development ranging between concrete and formal operational (abstract) thought; and (2) fifth graders can express their thoughts in written form. While the shift from concrete to abstract thought typically begins between the ages of 12 and 15 , such abilities as symbolization and the awareness of multiple features of objects and tasks do not become consolidated until late adolescence and beyond (Inhelder and Piaget, 1958; Niemark, 1975; Piaget, 1972; Siegler, 1976).

Subjects were recruited from local public schools in a medium-sized Midwest university town. A letter describing the study and its aims, and requesting parental permission to participate, was distributed to students in fifth-grade classes in two elementary schools, eighth-grade history classes in a junior high school, and twelfth-grade psychology and peer counseling classes in a high school. The high school classes were open to all seniors, and reflected a wide range of interests and scholastic abilities, according to the teachers and the principal. Approximately $80 \%$ of those invited in each grade returned the required parental permission slips. (See Table I.)

\section{Procedure}

The instruments, described below, were administered in group settings during regular 50-minute class periods in each grade. The administration was divided into two equal sessions given on different days, and was carried out by three advanced female clinical psychology doctoral students. Subjects reported on a short form the following demographic information: sex, grade, age, number and sex of siblings.

\section{Assessment of Abstract Thinking}

Formal operational thought occurs across multiple cognitive domains. Since the development of formal thought is not uniform across all domains,

Table I. Subjects

\begin{tabular}{|c|c|c|c|c|c|c|c|}
\hline \multirow[b]{2}{*}{ Grade } & \multirow[b]{2}{*}{$N$} & \multirow[b]{2}{*}{ Sex } & \multirow[b]{2}{*}{$N$} & \multirow[b]{2}{*}{$\begin{array}{c}\text { Mean age } \\
\text { (years) }\end{array}$} & \multicolumn{3}{|c|}{ Race } \\
\hline & & & & & Caucasian & Black & $\begin{array}{l}\text { Asian, } \\
\text { Arabic, } \\
\text { Hispanic }\end{array}$ \\
\hline 5 & 60 & $\begin{array}{c}\mathbf{M} \\
\mathbf{F}\end{array}$ & $\begin{array}{l}31 \\
29\end{array}$ & $\begin{array}{l}10.4 \\
10.3 \\
10.6\end{array}$ & 48 & 6 & 6 \\
\hline 8 & 60 & $\begin{array}{l}\mathbf{M} \\
\mathbf{F}\end{array}$ & $\begin{array}{l}29 \\
31\end{array}$ & $\begin{array}{l}13.6 \\
13.7 \\
13.5\end{array}$ & 49 & 6 & 5 \\
\hline 12 & 59 & $\begin{array}{l}\mathbf{M} \\
\mathbf{F}\end{array}$ & $\begin{array}{l}26 \\
33\end{array}$ & $\begin{array}{l}17.7 \\
17.7 \\
17.7\end{array}$ & 49 & 5 & 5 \\
\hline
\end{tabular}


a multimeasure approach is desirable (Case, 1985; Niemark, 1975). Accordingly, we assess abstract thinking in two ways. The balance beam task, a visual-perceptual test of the concept of proportionality, and an analogy test of verbal reasoning skills, are combined to provide a dual measure of level of abstract thinking.

\section{The Balance Beam Task}

The balance beam task has been used extensively over the past ten years to assess spatial/mathematical reasoning skills (Case, 1985; Siegler, 1976). In our modification of the task, the child views an actual balance beam, and then examines a series of seven drawings of the balance beam with five equidistant pegs on each side. Weights are pictured in various combinations on different pegs on either side, and the child judges whether the beam will balance, tip right, or tip left. The child explains his/her reasoning for the choice, and these judgments are rated using a scale designed to assess their cognitive-developmental level. Case (1985) has developed a neo-Piagetian theoretical analysis of the levels of performance children show in their efforts to solve various cognitive problems. Specific component skills are examined at six different stages in the evolution of these efforts. Two raters achieved a $92 \%$ agreement rate using a 6 point scale adapted from Case (1985). The final score for each subject was the mean of the ratings for the completed items.

\section{The Analogy Problem}

The analogy problem is a valuable measure of verbal abstract thinking. Children show the same trend toward increasing abstraction in their capacity to solve analogies as for the balance beam task. Studies by Lunzer (1965), Sternberg and Rifkin (1979), and Case (1985) have examined the cognitive skills required to solve analogies of varying complexity. Case (1985) gives a multistage account of the development of verbal reasoning in the analogies test, beginning with straightforward relations between items at ages 9 to 11 and ending in complex, multistage reasoning requiring an understanding of the abstract relations between the items at ages $15-18$. The measure consists of a series of 16 analogy problems developed by Case and Sandlos (Case, 1985), in turn based on those developed by Lunzer (1965). The problems range from simple to complex double-stage analogies, and five choices (including "don't know") are offered for each. A score is assigned by totaling the correct answers. 
Because of school district policy, no measures of intelligence or achievement were obtainable.

\section{Assessment of Psychological Mindedness to Self and Others}

Psychological Mindedness Toward Others (PO). A new instrument was developed to measure the complexity of the subject's understanding of the thoughts, feelings, and motives of others: the Fairy Tale task. In a group setting, subjects listen to shortened versions of two well-known fairy tales, "Cinderella" and "The Emperor's New Clothes." They then write their answers to questions designed to elicit their thinking about the protagonists' motives and affects. The questions for "Cinderella" are as follows: (1) What kind of person is Cinderella? Describe her. (2) Why was Cinderella so nice to people who were mean to her? Write some reasons why she acted that way. (3) Why were the stepsisters so mean to Cinderella? Write some reasons why they were so mean. The questions posed after "The Emperor's New Clothes" are as follows: (1) What kind of person is the Emperor? Describe him. (2) Why did he believe that he was wearing a beatiful new outfit? Write some reasons why he believed that. (3) The little boy was the one to say that the emperor wasn't wearing any clothes. Why did he say it instead of a grownup? Write some reasons why it was the little boy who spoke up.

The answers to these questions are rated for the cognitive level of psychological mindedness regarding others, using a 4-point scale. See Appendix.

Reliability of the ratings was tested using Cohen's kappa. For early ratings of the Cinderella questions, $\varkappa=0.82, \sigma=0.173$ was achieved, and for early ratings of the Emperor questions, $x=0.85 \sigma=0.147$. Reliability was checked on subsequent sets, each set consisting of responses from 5 fifth, eighth, and twelfth graders. These ratings showed some instability, ranging from $x=0.48 \sigma=0.111$ to $x=0.89, \sigma=0.107$. To maintain validity, three raters rated all six questions for each subject, and disagreements were resolved by consensus. The final score was the mean of the six consensus scores for each subject.

Psychological Mindedness Toward The Self. The instrument used to assess the child's capacity for self-understanding - the Picture Story - was based on the extensively used projective test developed by Murray (1938), the Thematic Apperception Test (TAT). In a group setting, subjects view two evocative photographs and then write a story about each one in a booklet provided. Presented in random order, one picture shows a child of 8-10 years of age and indeterminate gender looking at a broken guitar. The other shows a mother and three small children embracing in the foreground. In the background a man sits at a table eating. For each picture the subjects were given 
standard TAT instructions, to include a beginning, middle, and end in their story, and to tell what the people in the story are thinking and feeling. After both stories were written, subjects were asked to read and reflect on their first story, and write what they felt the story might tell about themselves, explaining the links between the story and their ideas about what the story reveals about them. The same directions were repeated for the second story.

The level of psychological mindedness shown in these reflections was then rated on a 6-point scale. This scale was constructed on the same basic principles as the others: increasing cognitive complexity, moving from simple, obvious ("surface") characteristics to the interaction of several different abstract psychological concepts about the self. The scale also assesses increasing capacity to engage in self-observation, moving from denial of the relevance of the story to the self to full acceptance and rich introspection about the self. See Appendix.

Reliability of the ratings was tested using Cohen's kappa. Early ratings for the first card achieved $\varkappa=0.787, \sigma=0.071$, and $\varkappa=0.686, \sigma=0.141$ for the second. Final consensus ratings were combined in a mean score.

\section{RESULTS}

Our measures of abstract reasoning show large increments from one grade to the next. The analogy measure yielded means of $7.12,9.68$, and 11.73 for Grades 5,8 , and 12 , respectively $(S D=2.73,3.11,2.26 ; F[2,179]$ $=46.49, p<.001$ ). The balance beam measure yielded means of $2.25,2.77$, and 3.13 for Grades 5,8 , and 12 , respectively $(S D=.633, .640, .802 ; F[2$, 179] $=23.96, p<.001$ ).

To examine the relationship between the measures of psychological mindedness and a more general assessment of abstract reasoning, we generated a combined total abstract reasoning score by normalizing and summing the balance beam and analogy scores. This total score also, of course, showed significant differences between grade levels: $F(2,179)=49.31, p<.001$.

These findings are consistent with a broad range of investigations of the development of abstract reasoning abilities. Neither of the abstract reasoning measures were affected by gender differences, also consistent with a long history of results on gender differences, recently reviewed by Feingold (1988). These factors, together with the consistent similarity of the correlation patterns of the two abstract reasoning measures on the dependent variables, justify a partial correlation test of their relationship, with grade level partialled out first. The partial correlation between the balance beam measure and the analogy measure for the total sample is $r=0.41, p<.001$. 


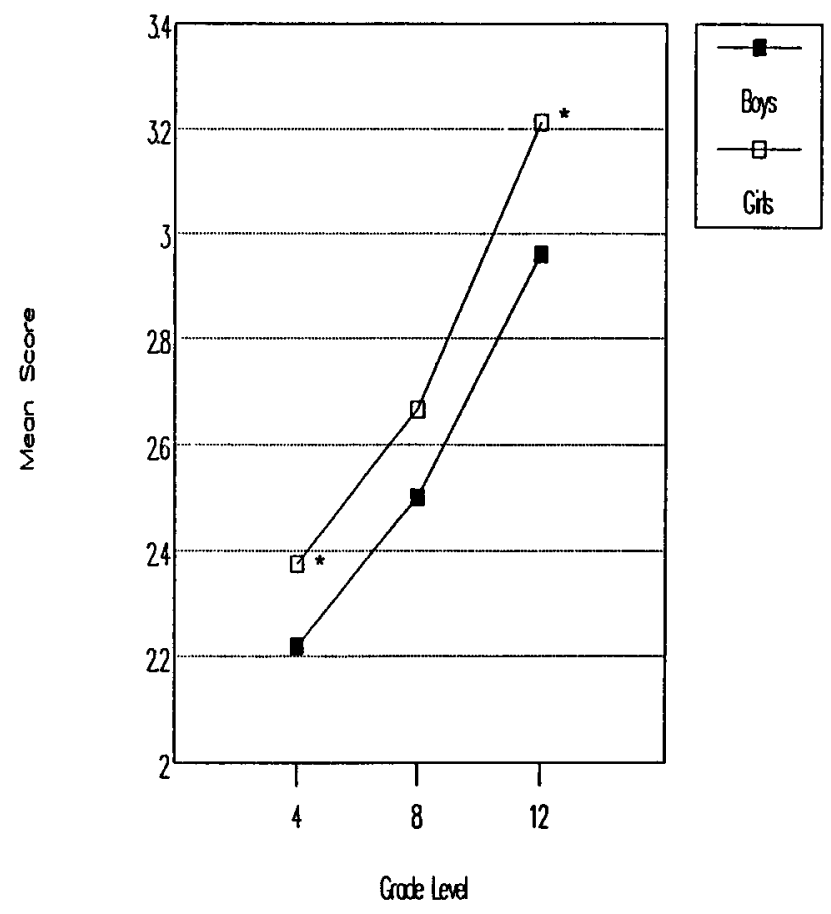

Fig. 1. Mean PO scores, boys vs. girls $\left({ }^{*} p<.05\right.$ for sex difference at this grade level).

Our first hypothesis is confirmed, as PO and PS each show dramatic gains from one grade to the next: $\mathrm{PO} F(2,178)=71.07, p<.001$; $\mathrm{PS} F(2$, 174) $=36.10, p<.001$.

Contrary to our second hypothesis, both of the major dependent variables, PO and PS, showed significant gender differences: $F(1,178)=12.24$, $p<.006$, and $F(1,174)=5.88, p<.01$, respectively. Girls scored higher than boys on both measures. Accordingly, the sample was split into two groups by gender, and further analyses were conducted on this basis. See Figs. 1 and 2.

Our exploration of the relationship between abstract reasoning and psychological mindedness yielded rather complex results. For male subjects (see Table II) PO is significantly correlated with abstract reasoning only in the fifth grade, although this relation approaches significance in the twelfth grade. PS is significantly correlated with abstract reasoning in the eighth grade only. 


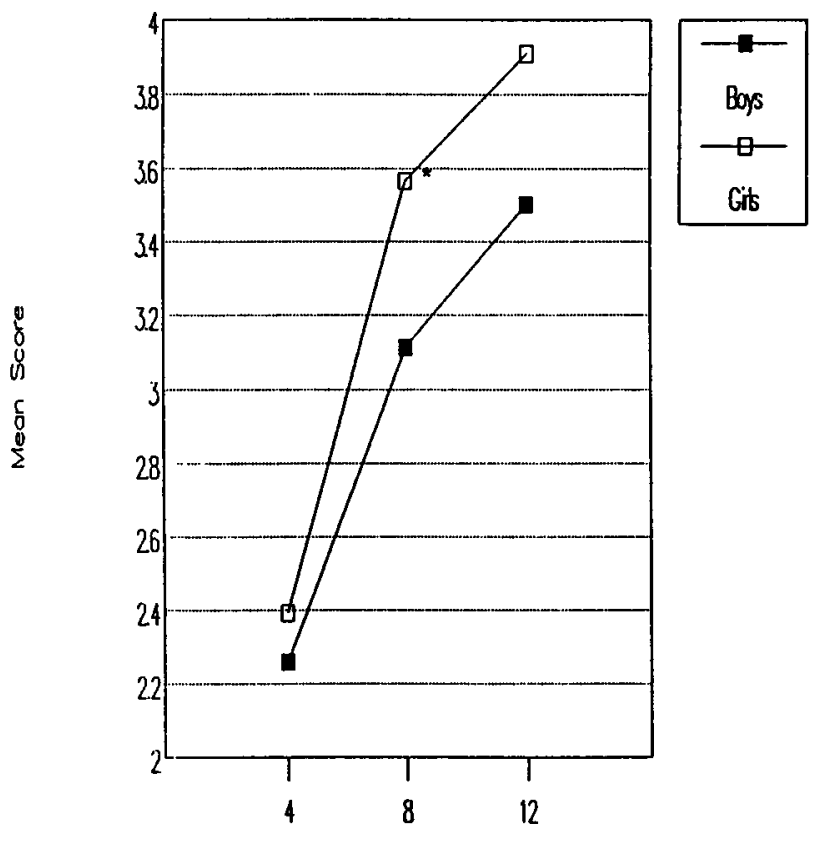

Cout Lend

Fig. 2. Mean PS scores, boys vs. girls $\left({ }^{*} p<.05\right.$ for sex difference at this grade level).

The pattern of findings for females was strikingly different (Table II). PO is significantly correlated with abstract reasoning only in the eighth-grade (as opposed to the fifth-grade) males. Unlike the boys, there is no correlation between PS and abstract reasoning for girls in any grade.

Our results (Table II) indicate few links between the two measures of psychological mindedness. In boys there is no significant correlation between the two measures at any grade. A significant correlation appears between the measures for twelfth-grade girls, however.

Histograms of the independent and dependent variables for each gradegender group were examined to determine if floor or ceiling effects were responsible for the findings. Each histogram showed ample variability, without skewedness to floor or ceiling.

Our results suggest that because the development of abstract reasoning skills does not directly correlate with our measures of the development of psychological mindedness in a simple way for either gender, a more complex model is called for. Also, performance on the two tasks measuring psy- 
Table II. Correlations by Grade and Sex for All Variables ${ }^{a}$

\begin{tabular}{|c|c|c|c|c|c|c|c|c|c|}
\hline \multicolumn{5}{|c|}{ Boys } & \multicolumn{5}{|c|}{ Girls } \\
\hline & An & BB & To & $\mathrm{PO}$ & & An & BB & To & $\mathrm{PO}$ \\
\hline \multicolumn{10}{|c|}{ Fifth grade } \\
\hline BB & .19 & .72 & & & $\mathrm{BB}$ & .28 & & & \\
\hline To & $.82^{d}$ & $.72^{d}$ & & & To & $.82^{d}$ & $.78^{d}$ & & \\
\hline PO & $.44^{c}$ & .28 & $.49^{d}$ & & PO & .22 & .09 & .19 & \\
\hline PS & -.21 & .01 & -.18 & -.30 & PS & -.22 & .15 & -.06 & .13 \\
\hline \multicolumn{10}{|c|}{ Eighth grade } \\
\hline BB & $.66^{d}$ & & & & BB & $.50^{d}$ & & & \\
\hline To & $.91^{d}$ & $.91^{d}$ & & & To & $.87^{d}$ & $.86^{d}$ & & \\
\hline PO & .14 & .03 & .10 & & PO & .21 & $.59^{d}$ & $.46^{d}$ & \\
\hline PS & $.53^{d}$ & $.51^{d}$ & .57 & .02 & PS & .22 & -.10 & .07 & -.02 \\
\hline \multicolumn{10}{|c|}{ Twelfth grade } \\
\hline BB & $.38^{b}$ & & & & BB & $.43^{c}$ & & & \\
\hline To & $.79^{d}$ & $.87^{d}$ & & & To & $.78^{d}$ & $.90^{d}$ & & \\
\hline PO & .20 & $.37^{b}$ & .35 & & $\mathrm{PO}$ & .23 & .09 & .17 & \\
\hline PS & -.08 & .16 & .06 & .26 & PS & -.19 & -.03 & -.11 & $.47^{d}$ \\
\hline
\end{tabular}

${ }^{a}$ An: analogy; BB: balance beam; To: total abstract reasoning; PO: psychological mindedness towards others; PS: psychological mindedness toward self.

${ }^{b} p<.07$.

$c_{p}<.05$.

chological mindedness does not covary directly and simply, suggesting that these may also be two qualitatively different psychological skills.

We infer the following trends in the results: PO begins as a skill connected with the ability to think abstractly. For girls, PO becomes autonomous and connected with self-observational skills (PS), but for boys it remains connected with the ability to think abstractly, and remains weakly linked to self-observational skills.

\section{DISCUSSION}

Many issues of interest arise from these findings, and from the measures themselves. This three-part discussion will (1) analyze the findings with regard to the initial hypotheses; (2) review and illustrate the measures of PS and PO; and (3) discuss the implications of these findings for clinical practice with children and adolescents, including applications for school guidance and peer counseling programs. 


\section{Hypotheses and Findings}

Our results show that the two aspects of psychological mindedness grow as children mature into adolescents. Psychological mindedness is indeed a developmental concept, although self-understanding and psychological understanding of others appear to follow two separate developmental lines and different gender patterning as well.

These findings are consistent with the existing literature on gender differences, where females are described as more interpersonal or "expressive" in their orientation to the world, while males are seen to be more achievement oriented or "instrumental" in their style (Gilligan, 1982; Chodorow, 1978; Bardwick, 1971). In modern Western culture it appears that the ability to understand oneself and to emphasize with others is a more "natural" personality trait for females. This may help explain the increasing national trend for more women than men to enter the mental health professions and for larger numbers of women to visit mental health clinics.

Our findings support Damon and Hart's (1982) call for caution in assuming that PO and PS develop together in a given individual. It would appear from this study that the ability to understand others (PO) is somewhat easier to attain than is self-understanding (PS) - a more complex and scarce commodity, and yet one so necessary for most insight-oriented psychotherapies. Piaget and Kohlberg show that abstract reasoning and mature moral reasoning are not reached by all grown-ups, and it seems too that not all individuals achieve the capacity for full self-observation. It should be possible, using the measures from this study, to assess a person's capacity for selfobservation and insight.

\section{Measures Used to Assess Self-Observation and Insight (PS) and Psychological Mindedness in Relation to Others (PO)}

The two measures provide clinical data to illustrate the statistical findings reported here. Analysis of self-observations on the Picture Story cards (PS) yields a number of intriguing patterns. Table III presents some of these findings.

Fifth, eighth, and twelfth graders' self-observations for the two story cards are generally typified by different content. While sibling conflicts were prevalent across the three grade levels, other topics were particular to each grade level.

In the fifth-grade sample we find many stories about orphanages, alcoholism, and abuse of children, most especially at the hands of fathers. 
Table III. Common Themes in Story Pictures Answers by Grade ${ }^{a}$

\begin{tabular}{lccccccccccc}
\hline $\begin{array}{l}\text { Grade } \\
\text { level }\end{array}$ & $\begin{array}{c}\text { Guitar } \\
\text { broken }\end{array}$ & Orphan & $\begin{array}{c}\text { Sub- } \\
\text { stance } \\
\text { abuse }\end{array}$ & $\begin{array}{c}\text { Phys- } \\
\text { ical } \\
\text { Death }\end{array}$ & $\begin{array}{c}\text { De- } \\
\text { abres- }\end{array}$ & $\begin{array}{c}\text { Talks } \\
\text { about } \\
\text { sion }\end{array}$ & $\begin{array}{c}\text { Di- } \\
\text { empathy }\end{array}$ & $\begin{array}{c}\text { Future } \\
\text { sasters }\end{array}$ & $\begin{array}{c}\text { Moals } \\
\text { task }\end{array}$ \\
\hline 5 & 14 & 7 & 3 & 19 & 11 & 0 & 0 & 14 & 0 & 0 \\
8 & 4 & 2 & 15 & 22 & 9 & 11 & 3 & 5 & 0 & 3 \\
12 & 5 & 3 & 10 & 5 & 22 & 12 & 8 & 0 & 15 & 8 \\
\hline
\end{tabular}

${ }^{a}$ All subjects received a score; some stories scored more than once.

Although the frequency of these tragic themes was striking, most stories by the younger children were assigned "happy endings." As is typical of younger children, many of the fifth graders personalized the task: "This story is about me, or our family," was a typical beginning. Such a beginning was more likely when the content related was not upsetting in nature. When it was, fifth graders were likely to deny the task, a typical response being, "It doesn't tell anything about me." Such denial was frequently employed as an apparent defense against painful affects such as sadness or guilt as was the case in the many stories about orphanages, kidnappings, abandonment, poverty, bodily injury, bombings, and tornadoes. Ilg and Ames (1955) describe similar themes as typical of ten-year-olds. It is clear that a child's capacity for PS may be restricted when conflictual themes are evoked. The cognitive skill may be present, but not used effectively.

The effect of a child's response to the first card was at times apparent on the story produced for the second one. When a fifth grader reported upsetting content for Card I, his/her insight score for Card II tended to be lower.

Themes of success or failure were frequent in this age group. Some fifth graders wondered whether or not the guitar would be fixed, whether the boy could earn enough money to buy a new one, or whether he might become "a world famous rock musician." Each of these solutions typifies the fifthgrade coping style, which tended to be concrete, to be personalized, and to demonstrate beginning struggles with moral issues.

Most issues of conscience at this relatively early stage of superego development were presented as shoulds or shouldn'ts, or in the form of a moralizing proverb.

In general, fifth graders produced brief and personalized selfobservations yielding less varied PS scores than the two older grades. Selfobservational skills are by no means the norm for fifth graders, so that therapists generally use displacement techniques (play therapy) in order to elicit affect and conflict. Nevertheless, it appears that some boys and girls in late elementary school show signs of an ability to observe their own feelings and motives. In general, however, the ability to self-observe is correlated with 
neither abstract reasoning nor PO. This finding disproves a portion of our third hypothesis, which states that those subjects who were more cognitively able within each grade level would also be more insightful about themselves. It seems likely that the younger child's need to protect him/herself from painful self-awareness makes it harder for her to use her developing capacities for psychological mindedness on herself.

While on a 6-point scale for self-understanding, only one fifth grader achieved a rating of 5 , by the eighth grade we see a much higher mean and a sprinkling of $6 \mathrm{~s}$, indicating for some subjects a very mature capacity for self-observation, although still not reaching twelfth-grade levels.

As we would expect from early to middle adolescents, eighth graders' stories are dramatically elaborated if not hyperbolic (S. Hatcher, 1973). There is pleasure in storytelling and elaborate use of language. While many of the eighth graders' stories are lengthy, this seems to have little to do with selfobservational skills since many of the long stories produce only superficial companion self-analyses.

Some eighth graders show an increasing awareness that their stories can reflect significant things about themselves. As one eighth grader observed, "I can learn that I have a distinct opinion and that I see and make things to be what I want them to be."

Many eighth-grade stories again concern child abuse, but now themes of drug and alcohol abuse and of mourning and depression appear. The latter themes may represent displaced expressions of sadness felt by youths trying to separate and individuate from their parents (A. Freud, 1958). Young adolescents typically show strong displays of emotions and moodiness, and some of our eighth graders "hate" one picture card or the other, and a few mock the task.

Noteworthy sequences of stories appeared across the two cards in the fifth- and eighth-grade sample. For eighth graders, a difficult first story is often not followed by a simple retreat in second story; the sequence at times suggests a more complex defense against the concerns of the first story. For example, one eighth grader tells us in the first story that she is angry at her father and in the second she invents a tale of his death. In her self-observation, quite remarkably, she is aware of the role of her angry motives in the creation of the second story.

Some eighth graders are able to produce very insightful and selfobservant reflections to their stories. Not only do words like "empathy" appear in their self-descriptions, but they seem to have this capacity in their psychological repertoire.

The twelfth graders show more consistent scores for their two stories than the volatile eighth graders. The consistency now comes not out of a failure to respond adequately to the task as was true for many of our young- 
est subjects but out of a more reliable ability to introspect thoughtfully. While eighth-grade stories were in many cases exaggerated and fantastic, the twelfth-grade tales are merely dramatic and narcissistic, much as we would expect from a population of middle to late adolescents. In a sense this group seems more defensive than the more open junior high school group. Many of the twelfth graders seemed wary of the task at hand. They not infrequently responded with sarcasm as a defensive posture, seemingly designed to guard their privacy. As one twelfth grader wrote for his self-observation to Card I,

You would probably think that I was somewhat of a dreamer because of the way the story ends. You'd probably think I'm very dramatic because of the (story). This probably could lead you into believing that I watch a lot of T.V. and my mental state has digressed to that of a carrot .... In reading this you probably would think I'm either joking or I was dropped by my mother when I was a baby.

Although this is a somewhat sarcastic response, there is some true selfobservation contained in it, and an awareness of the projective hypothesis involved in the task. Indeed, for the twelfth-grade sample there are frequent juxtapositions of both illusions of self-observation and true insight. For many high school subjects the notion that they are self-aware is an important aspect of their self-concept whether or not it is yet in fact the case. For others, as exemplified by the following subject, self-observation is already a reality: In reflecting on a story about her father's addiction to alcohol and her parents' subsequent divorce, one twelfth grader writes,

I think (the story) says that I am upset with how much my father and friends drink. I think it also says that I am upset with the way my dad treated me and my family before the divorce. I think it also says that I blamed myself for my parents' problems at the time of their divorce.

As one can see from this example, high school students are now capable of multiple and often complex self-observations. This age group tends to describe boyfriend-girlfriend relationships, loneliness, and conflicts with parents. Many write elegantly, even with a philosophical bent. One subject wrote for part of her self-observation,

... My writing deals a lot with emotions and how they link to the individual's thoughts. So I guess this makes me an emotional person. I deal with conflict, because as Mark Twain said, "without conflict you have no plot ...."

\section{Measure for Psychological Mindedness in Relation to Others (PO)}

The Fairy Tales were rated on a scale from less to more complex observation of the motives and feelings of others (PO). Across grades, many of the issues we have discussed for the PS task are found in the Fairy Tale measure. The younger sample tended to be concrete in its understanding of the 
two tales. Fifth graders often described Cinderella in such uncomplicated terms as "She is very sweet and kind." High school students, but also those younger subjects who scored higher than average on PO, gave such responses as "Cinderella had a low self-image and could not help herself."

When asked, "Why did the Emperor believe he was wearing a brand new outfit?" the younger subjects tended to give responses like "He didn't want to be thought of as stupid," while the more psychologically minded gave responses such as "He didn't want to feel like someone dogged him; he's a make believer."

It is important to note that the capacity for self-understanding and the ability to understand others turn out to be rather independent of each other. While both advance in general with age, they are not correlated except in twelfth-grade girls. This may be due in part to the increased defensiveness evoked by the self-observation task. While there could be some question about the twelfth graders' selection from a psychology and peer counseling class, there are indeed different levels of psychological mindedness exhibited within each grade including that of the oldest subjects. Furthermore the two skills (PO and PS) are not correlated for twelfth-grade boys, who were also selected from these same classes.

\section{Suggestions for Future Research}

It has been widely assumed (Damon and Hart, 1982) that children and indeed even adolescents would have difficulty profiting from an insightoriented psychotherapy - for these ages play therapy and more supportive interventions are the norm. Furthermore, peer counseling programs do not tend to emphasize insight but rather catharsis and support (Frenza, 1985).

Our data would suggest that many children and particulrly adolescents may be "ripe" for more psychologically minded interventions, either preventive or psychotherapeutic, prior to adulthood. High school girls may be particularly able to work in insight-oriented modalities as well as those boys in junior high and high school who are cognitively able. Perhaps readiness for psychologically minded interventions could be best determined on a caseby-case basis using assessment techniques similar to those suggested in this study.

Further research is recommended for refining the measures used here to assess self-observational ability and the capacity to function with psychological mindedness in relation to others, in order to make our scales more economically administered and coded. Longitudinal studies on this subject through and including adulthood would be of interest, as would the relevance of these measures on a cross-cultural basis. 
Of particular interest to the educational milieu would be the question of the "teachability" of the skills embodied in a two-pronged concept of psychological mindedness. The usefulness of these skills in preventive work with children and adolescents is obvious.

\section{ACKNOWLEDGMENTS}

The authors would like to express thanks to Dr. Ken Guire, Dr. Kay Saakvitne, Ms. Lisa Walsh, Ms. Christine Nadeau, Ms. Cindy Milner, and the administration and students in the Ann Arbor Public Schools for their help. Ms. Dawn Huebner contributed to the study, and used a version of our selfobservation measure in her doctoral thesis. Thanks also to the Department of Psychiatry, the University of Michigan, and the Dean's Office of the Rackham School of Graduate Studies, the University of Michigan, for helping to fund this research.

\section{REFERENCES}

Adelson, J., and Doehrman, M. J. (1980). The psychodynamic approach to adolescence. In Adelson, J. (ed.), The Handbook of Adolescent Psychology. John Wiley \& Sons, New York.

Adelson, J., and O'Neil, R. P. (1966). Growth of political ideas in adolescence: The sense of community. J. Personal. Social Psychol. 4: 295-306.

Baldwin, C. P., and Baldwin, A. L. (1970). Children's judgments of kindness. Child Develop. 41: $29-47$.

Bardwick, J. (1971). Psychology of Women. Harper \& Row, New York.

Bernstein, R. M. (1980). The development of the self system during adolescence. J. Gen. Psychol. 136: 231-245.

Broughton, J. (1980). The divided self in adolescence. Human Develop. 24: 13-32.

Case, R. (1985). Intellectual Development: Birth to Adulthood. Academic Press, New York.

Chodorow, N. (1974). Family structure and feminine personality. In Rosaldo, M. and Lamphere, L. (eds.), Woman, Culture and Society. Stanford University Press, Palo Alto, CA.

Chodorow, N. (1978). The Reproduction of Mothering: Psychoanalysis and the Sociology of Gender. University of California Press, Berkeley.

Clouter, R., and Goldschmid, M. (1976). Individual differences in the development of formal reasoning. Child Develop. 47: 1097-1102.

Damon, W., and Hart, D. (1982). The development of self understanding from infancy through adolescence. Child Develop. 53: 841-864.

Elkind, D. (1980). Strategic interactions in early adolescence. In Adleson, J. (ed.). Handbook of Adolescent Psychology. John Wiley \& Sons, New York.

Feingold, A. (1988). Cognitive gender differences are disappearing. Am. Psychol. 43: 95-103.

Flavell, J. H., Botkin, P. T., Fry, C. L., Wright, J. W., and Jarvis, P. E. (1968). The Development of Role Taking and Communication Skills in Children. John Wiley \& Sons. New York.

Frenza, M. (1985). Peer counseling (Report No. C6018821). Counseling and Personnel Services Clearinghouse, The University of Michigan, Ann Arbor (ERIC Document Reproduction Service No. ED266341).

Freud, A. (1958). Adolescence. In Esman, A. (ed.), The Psychology of Adolescence. International Universities Press, New York. 
Freud, A. (1979). The role of insight in psychoanalysis and psychotherapy: Introduction. $J$. Am. Psychoanal. Assoc. 27(supplement): 3-7.

Gilligan, C. (1979). Woman's place in man's life cycle. Harvard Educat. Rev. 49: 431-446.

Gilligan, C. (1982). In a Different Voice: Psychological Theory and Woman's Development. Harvard University Press, Cambridge, MA.

Goldschmid, M. L. (1968). The relation of conservation to emotional and environmental aspects of development. Child Develop. 39: 579-589.

Guargo, C. J., and Bohan J. B. (1971). Development of a sense of self identity in children. Child Develop. 42: 1909-1921.

Hatcher, R. L. (1972). Self observation in psychoanalytic psychotherapy. Unpublished doctoral dissertation, University of Michigan, Ann Arbor.

Hatcher, R. L. (1973). Insight and self-observation. J. Am. Psychoanal. Assoc. 21: 277-398.

Hatcher, S. (1973). The adolescent experience of pregnancy and abortion: A developmental analysis. J. Youth Adolesc. 2(1): 53-102.

Ilg, F., and Ames, L. (1955). Child Behavior. Harper \& Row, New York.

Inhelder, B., and Piaget, J. (1958). The Growth of Logical Thinking from Childhood to Adolescence. Basic Books, New York.

Kennedy, H. (1979). The role of insight in child analysis: A developmental viewpoint. J. Am. Psychoanal. Assoc. 27(supplement): 9-28.

King, M. (1971). The development of some intention concepts in young children. Child Develop. 42: 1145-1152.

Kohlberg, L. (1964). Development of moral character and moral ideology. In Hoffman, M. C., and Hoffman, L. V. (eds.), Review of Child Development Research, Vol. 1. Russell Sage Foundation, New York.

Lunzer, E. A. (1965). Problems of female reasoning in test situations. In Mussen, P. H. (ed.), European Research in Cognitive Development. Monographs of the Society for Research in Child Development, 30, 19-46.

Miller, P. H., Kessel, F. S., and Flavell, J. H. (1970). Thinking about people, thinking about people thinking about ... A study of social cognitive development. Child Develop. 41: 613-623.

Murray, H. (1938). Explorations in Personality. Oxford University Press, Fairlawn, NJ.

Niemark, E. D. (1975). Intellectual development during adolescence. In Horowitz, F. (ed.), Review of the Child Development Research. University of Chicago Press, Chicago.

Piaget, J. (1956). The Psychology of Intelligence. Routledge and Kegan Paul, London.

Piaget, J. (1969). The intellectual development of the adolescent. In Esman, A. (ed.), The Psychology of Adolescence. International Universities Press, New York.

Piaget, J. (1972). Intellectual evolution from adolescence to adulthood. Human Develop. 15: 1-12.

Rothenberg, B. B. Children's social sensitivity and the relationship to interpersonal competence, intrapersonal comfort, and intellectual level. Develop. Psychol. 2: 335350 .

Salatas, H., and Flavell, J. H. (1976). Perspective taking: The development of two components of knowledge. Child Develop. 47: 103-109.

Secord, P., and Peevers, B. (1974). The development and attribution of person concepts. In Mischel, T. (ed.), Understanding Other Persons. Blackwell, Oxford.

Selman, R. (1971). The relation of role taking to the development of moral judgment in children. Child Develop. 42: 79-91.

Selman, R. L., and Byrne, D. F. (1974). A structural-developmental analysis of levels of role taking in middle childhood. Child Develop. 45: 803-806.

Siegler, R. S. (1976). Three aspects of cognitive development. Cognitive Psychol. 8: 481-520.

Spiegel, L. (1951). A review of contributions to a psychoanalytic theory of adolescence. Psychoanal. Study Child 6: 375-393.

Sternberg, R. J., and Rifkin, B. (1979). The development of analogical reasoning processes. J. Exper. Child Psychol. 27: 195-232.

Whiteman, M. (1967). Children's conceptions of psychological causality. Child Develop. 38: 143-155. 
Appendix

\begin{tabular}{cc}
\hline Fairy Tale Coding Scale: Psychological Mindedness toward Others \\
\hline Scale category & Example \\
\hline
\end{tabular}

1. Unable to engage the task (no answer: scored as missing data).

2. a. Subject gives a direct quote or paraphrase of the story.

b. Subject uses simple, stock phrases, and ideas. These reflect "cliched" ideas that offer little new understanding beyond the story itself.

3. Subject uses a different perspective tht does not simply repeat the point of view of the story, but without the interacting motives or complex combinations of the next level.

4. Subject gives an account using higher level abstract concepts. Interacting psychological entities are recognized; concepts of internal conflict, need for self-deception; combinations of traits which work together.
“I don't know."

"They would think he was stupid if he told them he couldn't see it."

"She forgave them because she was nice."

"Two wrongs don't make a right."

"She was afraid of being punished."

"She didn't want to act like her stepsisters."

"Her parents taught her to be nice."

"He did not want to believe he was unfit to be emperor, and by believing he saw the cloth, he could believe he was fit to be emperor."

"She was so shy and reserved that she was afraid of them."

Scale category
1. The subject denies the relevance of the
question (no answer: scored as missing
data).
2. The subject negates or denies a personal
meaning of his or her response.

Picture Story Coding Scale: Psychological Mindedness toward the Self

3. a. The subject associates with the theme but does not reflect on his/her own thoughts, feelings, or motives.

b. The subject simply associates with a moral to the story without reflection on him/herself.

4. a. The subject straightforwardly attributes feelings to him/herself in response to the task.

b. The subject identifies with the character in the story with regard to one or more motivations for writing the story, but without seeing an interaction among them.

5. The subject's self-observation contains a complex set of motives with interactions among them. The subject recognizes his/her ambivalence or a conflict between two motives.
"The character in this story is rebellious but this is not true of me."

"I like war stories."

"I just have to find the good things in a situation."

"I am a caring person."

"I also feel that people don't like me."

"Like the girl in the story, I am jealous of my baby sister, even though I also love her." 
6. The subject understands his/her defen- "I, too, want to hide it when I am angry at sive maneuvers. others so I always act agreeable." 